\title{
Catastrophizing and depressive symptoms as prospective predictors of outcomes following total knee replacement
}

\author{
Robert R Edwards $\mathrm{PhD}^{1,2}$, Jennifer A Haythornthwaite $\mathrm{PhD}^{2}$, Michael T Smith $\mathrm{PhD}^{2}$, Brendan Klick ScM${ }^{2}$, \\ Jeffrey $\mathrm{N}$ Katz MD MSc ${ }^{3}$
}

RR Edwards, JA Haythornthwaite, MT Smith, B Klick, JN Katz. Catastrophizing and depressive symptoms as prospective predictors of outcomes following total knee replacement. Pain Res Manage 2009;14(4):307-311.

Several recent reports suggest that pain-related catastrophizing is a risk factor for poor acute pain outcomes following surgical interventions. However, it has been less clear whether levels of catastrophizing influence longer-term postoperative outcomes. Data were analyzed from a relatively small number $(n=43)$ of patients who underwent total knee replacement and were followed for 12 months after their surgery. Previous research has suggested that high levels of both catastrophizing and depression are associated with elevated acute postoperative pain complaints among patients undergoing knee surgery. In this sample, catastrophizing and depression at each of the assessment points were studied as prospective predictors of pain (both global pain ratings and pain at night) at the subsequent assessment point over the course of one year. The predictive patterns differed somewhat across measures of pain reporting; depressive symptoms were unique predictors of greater global pain complaints, while catastrophizing was a specific and unique predictor of elevated nighttime pain. While surgical outcomes following total knee replacement are, on average, quite good, a significant minority of patients continue to experience long-term pain. The present findings suggest that high levels of catastrophizing and depression may promote enhanced pain levels, indicating that interventions designed to reduce catastrophizing and depressive symptoms may have the potential to further improve joint replacement outcomes.

Key Words: Arthroplasty; Catastrophizing; Depression; Knee replacement; Pain

Total knee arthroplasty (TKA) is an increasingly common 1 treatment for advanced osteoarthritis or other types of arthritis of the knee. In the United States, more than 500,000 TKAs are performed each year; based on current trends, annual rates of knee replacement are expected to exceed 3.5 million within the next 25 years (1). The 2007 report of the Canadian Joint Replacement Registry revealed that TKA rates in Canada have increased $140 \%$ over the past decade, and are close to per capita TKA rates in the United States (2). In general, rates of surgical 'success' exceed $80 \%$, although success is rarely defined by complete pain relief. Indeed, it is clear that a substantial number of TKA recipients persistently complain of significant pain despite normal radiographs, unremarkable physical examinations and even self-reported 'good' outcomes (3-6). Numerous surveys regarding post-TKA quality of life have documented ongoing 'average' rates of mild to moderate pain at

\section{La catastrophisation et les symptômes de dépression comme prédicteurs prospectifs d'issues après une arthroplastie totale du genou}

Selon plusieurs rapports récents, la catastrophisation liée à la douleur est un facteur de risque d'issues négatives de douleur aiguë après une intervention chirurgicale. Cependant, il n'est pas établi aussi clairement si le taux de catastrophisation influe sur les issues postopératoires à plus long terme. Les données étaient analysées à partir d'un échantillon relativement limité $(n=43)$ de patients qui avaient subi une arthroplastie totale du genou et avaient été suivis pendant 12 mois après leur opération. Des recherches antérieures indiquent que des taux élevés de catastrophisation et de dépression s'associent à un taux élevé d'allégations de douleur postopératoire aiguë chez les patients qui subissent une arthroplastie. Dans cet échantillon, on a étudié la catastrophisation et la dépression à chacun des points d'évaluation à titre de prédicteurs prospectifs de la douleur (à la fois les évaluations globales de la douleur et la douleur nocturne) au point d'évaluation suivant tout au long de l'année. Les motifs prédictifs différaient quelque peu entre les mesures de déclaration de douleur. Ainsi, les symptômes de dépression étaient des prédicteurs uniques d'allégations de douleur globale plus aiguë, tandis que la catastrophisation était un prédicteur spécifique et unique d'intense douleur nocturne. Tandis qu'en moyenne, les issues chirurgicales après une arthroplastie totale du genou sont plutôt positives, une forte minorité de patients continue de souffrir de douleurs à long terme. D'après les présentes observations, des taux élevés de catastrophisation et de dépression peuvent promouvoir des taux de douleur plus vive, ce qui laisse supposer que des interventions conçues pour réduire les symptômes de catastrophisation et de dépression pourraient améliorer les issues après une arthroplastie.

six months (7), one year (8), two years (9) and three years (10) postsurgery. The most recent reviews and long-term follow-up studies suggest that, one year after TKA, up to one-fourth of patients continue to report substantial pain and functional limitations. For example, a British study of more than 600 TKA patients five to eight years postsurgery indicated that $26 \%$ reported ongoing moderate to severe pain (11). Collectively, it is quite clear that pain remains a significant long-term problem for a number of patients after knee replacement, with wide individual variability in the course of painrelated outcomes over time (eg, some patients report minimal pain shortly after surgery, while others describe ongoing moderate to severe pain that persists for years). Psychosocial processes such as emotional distress and social support appear to be important in shaping the long-term course of post-TKA outcomes (7), but research in this area remains in its infancy.

${ }^{1}$ Department of Anesthesiology, Perioperative and Pain Medicine, Harvard Medical School, Brigham Eु Women's Hospital, Chestnut Hill, Massachusetts; ${ }^{2}$ Department of Psychiatry and Behavioral Sciences, Johns Hopkins University School of Medicine, Baltimore, Maryland; ${ }^{3}$ Department of Orthopedic Surgery and Division of Rheumatology, Harvard Medical School, Brigham Eु Women's Hospital, Chestnut Hill, Massachusetts, USA

Correspondence: Dr Robert R Edwards, Pain Management Center, Brigham E⿱ Women's Hospital, 850 Boylston Street, Chestnut Hill, Massachusetts 02467, USA. Telephone 617-732-9486, fax 617-732-9050, e-mail RREdwards@partners.org 
One psychological variable that has repeatedly been shown to influence pain-related outcomes across a variety of domains is catastrophizing, a negative cognitive and affective response to pain (12). The construct of catastrophizing incorporates magnification of pain-related symptoms, excessive attentional focus on pain, rumination about pain, feelings of helplessness when in pain and pessimism about pain-related outcomes (13). In cross-sectional studies in osteoarthritis patients, catastrophizing correlates with higher pain severity $(14,15)$, higher levels of observed pain behaviours and functional limitations during standardized activity tests (15), and lower pain threshold and tolerance (16). In addition, several knee surgery studies have reported prospective associations of catastrophizing with short-term negative outcomes. For example, in patients undergoing ligament repair, higher preoperative catastrophizing scores predicted more severe postoperative pain over the course of the first postsurgical week (17). In addition, a study of TKA patients noted that higher preoperative levels of catastrophizing were associated with longer times to achieve postsurgery functional targets such as $90^{\circ}$ flexion (18).

The current literature lacks dynamic study of the interplay between catastrophizing and pain over the course of recovery from knee replacement. Research in samples of patients with other pain conditions has suggested that negative affective and cognitive processes may act to impede recovery following painreducing interventions (eg, in sciatica patients undergoing surgery or conservative management [19]). If similar effects operate following TKA, these associations could have potentially important pain management implications. In addition, many previous studies of catastrophizing have not controlled for more general measures of distress (12). Because some studies have found that depression (20-22) is related to fewer improvements in pain and function after joint replacement, and because depression and catastrophizing are significantly intercorrelated (12), we believed it was important to include measures of both catastrophizing and depression in our predictive models. In the present report, we assess prospective relationships over a one-year post-TKA period between catastrophizing, depressive symptoms and knee pain. We evaluated both global pain ratings and ratings of pain at night, because disrupted sleep has negative long-term consequences for pain-related outcomes $(23,24)$.

\section{METHODS}

\section{Participants}

Participants with intractable knee pain who were scheduled for unilateral knee replacement were recruited from the Johns Hopkins Department of Orthopedic Surgery (Baltimore, Maryland, USA). The study protocol called for a brief set of questionnaires to be administered to patients at five time points - presurgery, as well as one month, three months, six months and 12 months postsurgery. Because of research staffing constraints, only a small number of patients were recruited; a total of 43 patients provided data for at least two time points, and were thus eligible for inclusion in the present sample. Sample sizes for each assessment point were as follows: presurgery, $n=20$; one month postsurgery, $n=29$; three months postsurgery, $n=38$; six months postsurgery, $n=38$; and one year postsurgery, $n=32$. Although these sample sizes were small, the inclusion of repeated assessments and the use of longitudinal data-analytic techniques that used all available data while accounting for missing observations helped to improve study power.

\section{Measures}

Data were derived from questionnaires completed by patients during clinic visits; at each time point, subjects completed the measures listed below.

Coping Strategies Questionnaire catastrophizing subscale: The Coping Strategies Questionnaire (CSQ) catastrophizing subscale assesses the frequency of catastrophizing cognitions and emotions in the context of pain (eg, "when I feel pain...I worry all the time about whether it will end") (25). Respondents rated items from 0 ('never' use that strategy) to 6 ('always' use that strategy). The six-item CSQ catastrophizing subscale is a commonly used measure of catastrophizing (12); it possesses good psychometric properties and, in the present sample, had a Cronbach's alpha of 0.88 .

Center for Epidemiological Studies Depression Scale: The Center for Epidemiological Studies Depression Scale (CES-D) is a widely used self-report measure that assesses depressive cognitions, dysphoric mood and vegetative symptoms (26). It contains 20 items; respondents rate how frequently in the previous week they experienced each symptom. Cronbach's alpha for the CES-D was 0.79 in the present sample.

Pain severity: Two types of pain ratings were analyzed - overall pain severity ( 0 to 100 ) in the past $48 \mathrm{~h}$, and nighttime pain (ie, "pain at night while trying to sleep", also rated from 0 to 100). Nighttime pain was included as an outcome variable because several recent studies have highlighted important inter-relationships between catastrophizing and sleep/ fatigue in the context of pain (27-30). Recall of recent pain (over the past $24 \mathrm{~h}$ to $48 \mathrm{~h}$ ) and, similarly, brief pain items are commonly used and well-validated outcome measures $(31,32)$.

\section{Data reduction and analysis}

To assess the prospective contributions of catastrophizing to pain outcomes, a repeated measures analysis was performed using data from all follow-up time points from baseline to 12-month follow-up. For longitudinal data of this type, mixed model or generalized estimating equation (GEE) approaches to data analysis are typically preferred to standard ANOVA techniques because they take into account missing data and withinsubject correlations. Therefore, GEEs were used to model the correlation structure of the repeated measures within each patient. In each GEE model, the predictor variables of primary interest were the CSQ catastrophizing subscale and total CES-D score, assessed at the previous time point, as predictors of pain at the subsequent time point. Thus, these models represent what are typically referred to as 'lagged analyses', evaluating the prospective effects of the predictor variables on future values of the dependent variables. In each model, time and pain at the previous time point were also included as predictors, permitting the evaluation of the prospective association between catastrophizing and subsequent pain, independent of previous pain levels (in effect, to study the association between catastrophizing and changes in pain). For each model, the effect of catastrophizing is presented before and after the inclusion of depressive symptomatology scores. Findings from the reverse model, with pain as a prospective predictor of 
TABLE 1

Pain, catastrophizing and depression scores at each study time point

\begin{tabular}{lccccc}
\hline & Pre- & \multicolumn{4}{c}{ Postsurgery } \\
\cline { 3 - 6 } Variable & surgery & 1 month & 3 months 6 months & 12 months \\
\hline $\begin{array}{c}\text { Global daily pain } \\
(0-100)^{* *}\end{array}$ & $58.8 \pm 23.0$ & $29.8 \pm 26.6$ & $21.0 \pm 25.9$ & $13.3 \pm 19.9$ & $11.0 \pm 19.7$ \\
$\begin{array}{c}\text { Nighttime pain } \\
(0-100)^{* *}\end{array}$ & $40.7 \pm 32.1$ & $31.5 \pm 29.8$ & $18.1 \pm 23.7$ & $11.6 \pm 19.6$ & $8.9 \pm 16.8$ \\
$\begin{array}{c}\text { CSQ catastrophizing } \\
\text { subscale }(0-36)\end{array}$ & $3.8 \pm 3.9$ & $4.5 \pm 6.4$ & $4.4 \pm 5.1$ & $4.0 \pm 5.4$ & $3.8 \pm 5.4$ \\
CES-D $(0-60)^{*}$ & $12.1 \pm 6.8$ & $13.9 \pm 7.5$ & $11.8 \pm 7.4$ & $9.8 \pm 6.6$ & $7.8 \pm 5.3$ \\
\hline
\end{tabular}

Data presented as mean $\pm S D$. ${ }^{*} P<0.01 ;{ }^{* *} P<0.001$ for the repeated measures test of changes over time. CES-D Center for Epidemiological Studies Depression Scale; CSQ Coping Strategies Questionnaire

catastrophizing, are not presented because catastrophizing levels did not change significantly over the course of the 12 -month follow-up.

\section{RESULTS}

Sample characteristics

Fifty-eight per cent of the participants were women, and the mean $( \pm \mathrm{SD})$ age of the sample was $71.7 \pm 7.0$ years. Data collection proved most difficult at the presurgery time point (ie, the sample size was smallest then); those subjects who provided presurgical data did not differ from those who provided only postsurgical data with respect to age, sex and measures of pain, catastrophizing, and depression at three months postsurgery (ie, where the sample size peaked) (all $\mathrm{P}<0.30$ ). Table 1 presents the values at each time point for pain, catastrophizing and depressive symptoms. As expected, ratings of both global and nighttime pain decreased substantially from presurgery values over the course of a one-year follow-up $(\mathrm{P}<0.001)$, and levels of depressive symptoms also declined over the follow-up period $(\mathrm{P}<0.01)$. In contrast, catastrophizing did not change significantly over the course of the study $(\mathrm{P}>0.40)$. Catastrophizing and CES-D scores were significantly positively associated at each time point, with intercorrelations ranging from $\mathrm{r}=0.36(\mathrm{P}<0.05)$ at three months to $\mathrm{r}=0.71(\mathrm{P}<0.001)$ at six months, and a mean correlation coefficient of 0.56 .

\section{Predicting global pain ratings}

In the GEE analysis predicting global daily pain scores over the one-year follow-up period, previous pain score was a robust predictor of future pain scores, as expected. Catastrophizing was a significant $(\mathrm{P}<0.05)$ prospective predictor $(\mathrm{ie}$, higher catastrophizing was associated with higher daily pain severity) of daily pain severity in the model that did not include depressive symptoms as a predictor, but when CES-D scores were included in the model, only CES-D scores emerged as significant predictors of subsequent daily pain ratings $(\mathrm{P}<0.05)$. A detailed presentation of these effects is shown in Table 2.

\section{Predicting nighttime pain}

In the GEE analysis predicting nighttime pain scores over the one-year follow-up period, previous nighttime pain score was, again, a highly significant predictor of future nighttime pain scores. Catastrophizing was a significant $(\mathrm{P}<0.05)$ prospective predictor of nighttime pain in the models with and without depressive symptoms. In contrast to the model predicting global pain ratings, CES-D scores did not emerge as significant
TABLE 2

Results of generalized estimating equation model assessing predictors of global daily pain ratings

\begin{tabular}{llccc}
\hline Predictor variable & \multicolumn{3}{c}{ Standard } \\
\hline Model without CES-D scores & Estimate & error & $\boldsymbol{t}$ & $\mathbf{P}$ \\
$\quad$ Time & 1.4 & 3.2 & 0.4 & 0.67 \\
Pain at previous time point & 0.48 & 0.07 & 6.7 & $<0.001$ \\
Catastrophizing at previous time point & 4.6 & 1.9 & 2.4 & 0.02 \\
Model with CES-D scores & & & & \\
Time & 1.7 & 3.2 & 0.5 & 0.60 \\
Pain at previous time point & 0.43 & 0.08 & 5.8 & $<0.001$ \\
Catastrophizing at previous time point & 2.1 & 2.2 & 0.9 & 0.35 \\
CES-D at previous time point & 0.67 & 0.30 & 2.2 & 0.03 \\
\hline
\end{tabular}

CES-D Center for Epidemiological Studies Depression Scale

\section{TABLE 3}

Results of generalized estimating equation model assessing predictors of nighttime pain ratings

\begin{tabular}{lcccc}
\hline & \multicolumn{3}{c}{ Standard } \\
Predictor variable & Estimate & error & $\boldsymbol{t}$ & $\mathbf{P}$ \\
\hline Model without CES-D scores & & & & \\
$\quad$ Time & -4.0 & 3.4 & -1.2 & 0.24 \\
Nighttime pain at previous time point & 0.35 & 0.08 & 4.4 & $<0.001$ \\
Catastrophizing at previous time point & 6.4 & 2.2 & 2.9 & 0.005 \\
Model with CES-D scores & & & & \\
Time & -3.9 & 3.5 & -1.1 & 0.27 \\
Nighttime pain at previous time point & 0.32 & 0.08 & 3.8 & $<0.001$ \\
Catastrophizing at previous time point & 5.1 & 2.5 & 2.0 & 0.04 \\
CES-D at previous time point & 0.40 & 0.33 & 1.2 & 0.24 \\
\hline
\end{tabular}

CES-D Center for Epidemiological Studies Depression Scale

predictors of future nighttime pain scores (Table 3 ). The addition of a time $\times$ catastrophizing interaction was nonsignificant, suggesting that the association between catastrophizing and subsequent nighttime pain was relatively constant across the study period.

\section{DISCUSSION}

The present study was the first to simultaneously evaluate the predictive influence of catastrophizing and depression on postTKA pain over a period of one year postsurgery. Interestingly, and consistent with at least one previous study of orofacial pain (33), catastrophizing was unaltered following large changes in the severity of clinical pain (ie, despite the substantial resolution of knee pain, reported levels of catastrophizing did not decrease while depressive symptoms, as measured by the CES-D, diminished steadily). This suggests a substantial stability, or 'trait' component, to the construct of catastrophizing, and hints that high levels of catastrophizing may warrant intervention in their own right (12).

Consistent with previous reports $(21,22,34)$, we observed that individual differences in depressive symptoms at one time point predicted global daily pain ratings at the next time point following TKA. Moreover, the moderate overlap between reports of catastrophizing and depression was evident in the finding that inclusion of depressive symptoms in the model substantially reduced the predictive power of catastrophizing. Interestingly, however, a similar effect did not emerge for the model predicting nighttime pain, and catastrophizing remained a unique prospective predictor even after the inclusion of 
CES-D scores. One explanation for this differential pattern of findings may lie in previous reports that catastrophizing is associated with poor sleep and symptoms of insomnia $(35,36)$, above and beyond the general effects of distress and depression (36). If catastrophizing specifically results in greater time awake at night (eg, longer sleep latency and more frequent awakenings), then high-catastrophizing participants would be expected to remember and report greater nighttime pain. Alternatively, expectations could play a role; daytime, userelated pain may be generally expected by patients post-TKA, but it may be solely the high catastrophizers who anticipate nighttime pain, which may then influence their sleep and pain experience over the course of the night.

Collectively, overwhelming evidence suggests that cognitive and affective factors are intimately involved in the pain experience (12,37-39). In previous studies, high levels of catastrophizing have been associated with a variety of deleterious pain-related outcomes, including the onset of phantom limb pain after amputation (40), the development of chronic back or neck pain $(41,42)$, enhanced neural responses to painful stimulation $(43,44)$, and greater health care costs in individuals with chronic pain (45). The present report, although limited by its small sample size and substantial missing data, adds to the existing literature by suggesting that ongoing catastrophizing and depression may act to inhibit the long-term pain-reducing effects of TKA, with catastrophizing and depression promoting enhanced levels of nighttime pain and daily pain, respectively. Although these results await replication in a larger sample, such findings suggest that catastrophizing and depression may be productively targeted post-TKA as a means of improving long-term pain-related outcomes. Logical next steps in this line of research involve study of the potential analgesic effects of catastrophizing- and depressionreducing interventions such as cognitive behavioural therapy (46) at a variety of time points before or after TKA.

ACKNOWLEDGEMENTS: This work was supported by a grant from the Johns Hopkins Blaustein Pain Research fund, NIH K23 AR051315 (to RRE), NIH K24 AR02123 (JNK), NIH P60 AR47782 (JNK) and NIH K24 NS02225 (JAH).

\section{REFERENCES}

1. Kurtz S, Ong K, Lau E, Mowat F, Halpern M. Projections of primary and revision hip and knee arthroplasty in the United States from 2005 to 2030. J Bone Joint Surg Am 2007;89:780-5.

2. Canadian Institute for Health Information. Canadian Joint Replacement Registry (CJRR) 2007 Annual Report - Hip and Knee Replacements in Canada. Ottawa: CIHI, 2008.

3. St Clair SF, Higuera C, Krebs V, Tadross NA, Dumpe J, Barsoum WK. Hip and knee arthroplasty in the geriatric population. Clin Geriatr Med 2006;22:515-33.

4. Katz JN. Total joint replacement in osteoarthritis. Best Pract Res Clin Rheumatol 2006;20:145-53.

5. Woolhead GM, Donovan JL, Dieppe PA. Outcomes of total knee replacement: A qualitative study. Rheumatology (Oxford) 2005;44:1032-7.

6. Wylde V, Dieppe P, Hewlett S, Learmonth ID. Total knee replacement: Is it really an effective procedure for all? Knee 2007;14:417-23.

7. Escobar A, Quintana JM, Bilbao A, et al. Effect of patient characteristics on reported outcomes after total knee replacement. Rheumatology (Oxford) 2007;46:112-9.

8. Wells V, Hearn T, Heard A, Lange K, Rankin W, Graves S. Incidence and outcomes of knee and hip joint replacement in veterans and civilians. ANZ J Surg 2006;76:295-9.

9. Escobar A, Quintana JM, Bilbao A, Arostegui I, Lafuente I, Vidaurreta I. Responsiveness and clinically important differences for the WOMAC and SF-36 after total knee replacement. Osteoarthritis Cartilage 2007;15:273-80.

10. Núñez M, Núñez E, del Val JL, et al. Health-related quality of life in patients with osteoarthritis after total knee replacement: Factors influencing outcomes at 36 months of follow-up. Osteoarthritis Cartilage 2007;15:1001-7.

11. Wylde V, Blom AW, Whitehouse SL, Taylor AH, Pattison GT, Bannister GC. Patient-reported outcomes after total hip and knee arthroplasty: Comparison of midterm results. J Arthroplasty 2009;24:210-6.

12. Edwards RR, Bingham CO III, Bathon J, Haythornthwaite JA. Catastrophizing and pain in arthritis, fibromyalgia, and other rheumatic diseases. Arthritis Rheum 2006;55:325-32.

13. Sullivan MJ, Thorn B, Haythornthwaite JA, et al. Theoretical perspectives on the relation between catastrophizing and pain. Clin J Pain 2001;17:52-64.

14. Keefe FJ, Affleck G, France CR, et al. Gender differences in pain, coping, and mood in individuals having osteoarthritic knee pain: A within-day analysis. Pain 2004;110:571-7.

15. Keefe FJ, Lefebvre JC, Egert JR, Affleck G, Sullivan MJ, Caldwell DS. The relationship of gender to pain, pain behavior, and disability in osteoarthritis patients: The role of catastrophizing. Pain 2000;87:325-34.

16. France CR, Keefe FJ, Emery CF, et al. Laboratory pain perception and clinical pain in post-menopausal women and age-matched men with osteoarthritis: Relationship to pain coping and hormonal status. Pain 2004;112:274-81.

17. Pavlin DJ, Sullivan MJ, Freund PR, Roesen K. Catastrophizing: A risk factor for postsurgical pain. Clin J Pain 2005;21:83-90.

18. Kendell K, Saxby B, Farrow M, Naisby C. Psychological factors associated with short-term recovery from total knee replacement. Br J Health Psychol 2001;6:41-52.

19. Edwards RR, Klick B, Buenaver L, et al. Symptoms of distress as prospective predictors of pain-related sciatica treatment outcomes. Pain 2007;130:47-55.

20. Fisher DA, Dierckman B, Watts MR, Davis K. Looks good but feels bad: Factors that contribute to poor results after total knee arthroplasty. J Arthroplasty 2007;22:39-42.

21. Brander V, Gondek S, Martin E, Stulberg SD. Pain and depression influence outcome 5 years after knee replacement surgery. Clin Orthop Relat Res 2007;464:21-6.

22. Brander VA, Stulberg SD, Adams AD, et al. Predicting total knee replacement pain: A prospective, observational study. Clin Orthop Relat Res 2003;27-36.

23. Edwards RR, Almeida DM, Klick B, Haythornthwaite JA, Smith MT. Duration of sleep contributes to next-day pain report in the general population. Pain 2008;137:202-7.

24. Smith MT, Klick B, Kozachik S, et al. Sleep onset insomnia symptoms during hospitalization for major burn injury predict chronic pain. Pain 2008;138:497-506.

25. Rosenstiel AK, Keefe FJ. The use of coping strategies in chronic low back pain patients: Relationship to patient characteristics and current adjustment. Pain 1983;17:33-44.

26. Radloff LS. The CES-D scale: A self-report depression scale for research in the general population. Appl Psychol Meas 1977;1:385-401.

27. Roth RS, Geisser ME, Theisen-Goodvich M, Dixon PJ. Cognitive complaints are associated with depression, fatigue, female sex, and pain catastrophizing in patients with chronic pain. Arch Phys Med Rehabil 2005;86:1147-54.

28. Raak R, Wikblad K, Raak A Sr, Carlsson M, Wahren LK. Catastrophizing and health-related quality of life: A 6-year follow-up of patients with chronic low back pain. Rehabil Nurs 2002;27:110-6.

29. Nijs J, Meeus M, De Meirleir K. Chronic musculoskeletal pain in chronic fatigue syndrome: Recent developments and therapeutic implications. Man Ther 2006;11:187-91.

30. Jacobsen PB, Andrykowski MA, Thors CL. Relationship of catastrophizing to fatigue among women receiving treatment for breast cancer. J Consult Clin Psychol 2004;72:355-61.

31. Jensen MP, Mardekian J, Lakshminarayanan M, Boye ME. Validity of 24-h recall ratings of pain severity: Biasing effects of "Peak" and "End" pain. Pain 2008;137:422-7. 
32. Tan G, Jensen MP, Thornby JI, Shanti BF. Validation of the Brief Pain Inventory for chronic nonmalignant pain. J Pain 2004;5:133-7.

33. Edwards RR, Fillingim RB, Maixner W, Sigurdsson A,

Haythornthwaite J. Catastrophizing predicts changes in thermal pain responses after resolution of acute dental pain. J Pain 2004;5:164-70.

34. Caracciolo B, Giaquinto S. Self-perceived distress and selfperceived functional recovery after recent total hip and knee arthroplasty. Arch Gerontol Geriatr 2005;41:177-81.

35. Karoly P, Ruehlman LS. Psychosocial aspects of pain-related life task interference: An exploratory analysis in a general population sample. Pain Med 2007;8:563-72.

36. Smith MT, Perlis ML, Carmody TP, Smith MS, Giles DE. Presleep cognitions in patients with insomnia secondary to chronic pain. J Behav Med 2001;24:93-114.

37. Keefe FJ, Abernethy AP, Campbell C. Psychological approaches to understanding and treating disease-related pain. Ann Rev Psychol 2005;56:601-30.

38. Gureje O. Psychiatric aspects of pain. Curr Opin Psychiatry 2007;20:42-6.

39. Gureje O, Von Korff M, Kola L, et al. The relation between multiple pains and mental disorders: Results from the World Mental Health Surveys. Pain 2008;135:82-91.
40. Richardson C, Glenn S, Horgan M, Nurmikko T. A prospective study of factors associated with the presence of phantom limb pain six months after major lower limb amputation in patients with peripheral vascular disease. J Pain 2007;8:793-801.

41. Picavet HS, Vlaeyen JW, Schouten JS. Pain catastrophizing and kinesiophobia: Predictors of chronic low back pain. Am J Epidemiol 2002;156:1028-34.

42. Carroll LJ, Cassidy JD, Cote P. The role of pain coping strategies in prognosis after whiplash injury: Passive coping predicts slowed recovery. Pain 2006;124:18-26.

43. Gracely RH, Geisser ME, Giesecke T, et al. Pain catastrophizing and neural responses to pain among persons with fibromyalgia. Brain 2004;127:835-43.

44. Seminowicz DA, Davis KD. Cortical responses to pain in healthy individuals depends on pain catastrophizing. Pain 2006;120:297-306.

45. Severeijns R, Vlaeyen JW, Van den Hout MA, Picavet HS. Pain catastrophizing is associated with health indices in musculoskeletal pain: A cross-sectional study in the Dutch community. Health Psychol 2004;23:49-57.

46. Turner JA, Mancl L, Aaron LA. Short- and long-term efficacy of brief cognitive-behavioral therapy for patients with chronic temporomandibular disorder pain: A randomized, controlled trial. Pain 2006;121:181-94. 


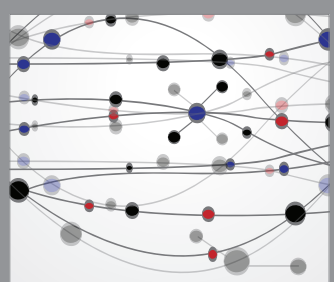

The Scientific World Journal
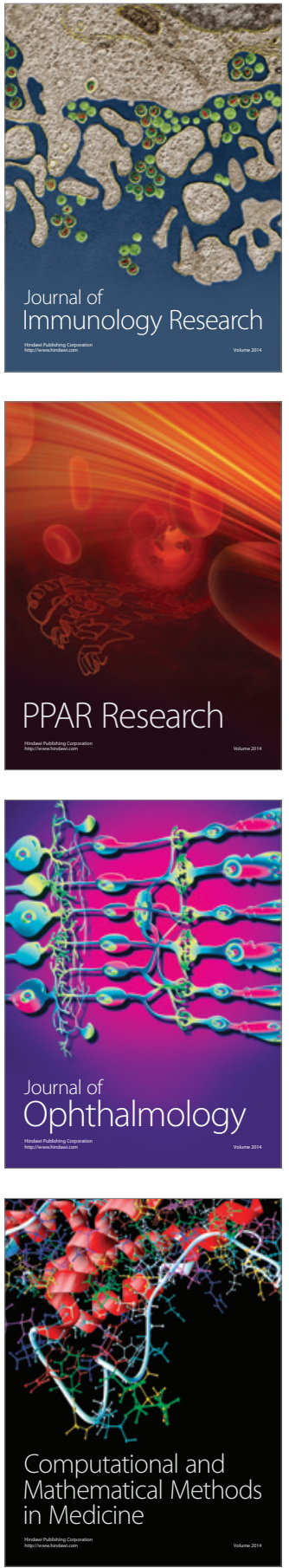

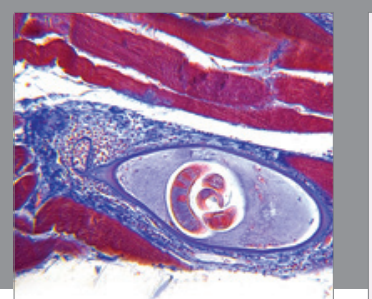

Gastroenterology Research and Practice

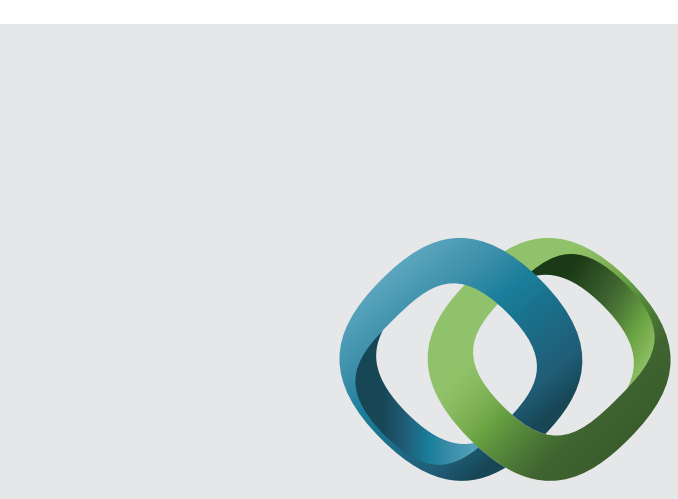

\section{Hindawi}

Submit your manuscripts at

http://www.hindawi.com
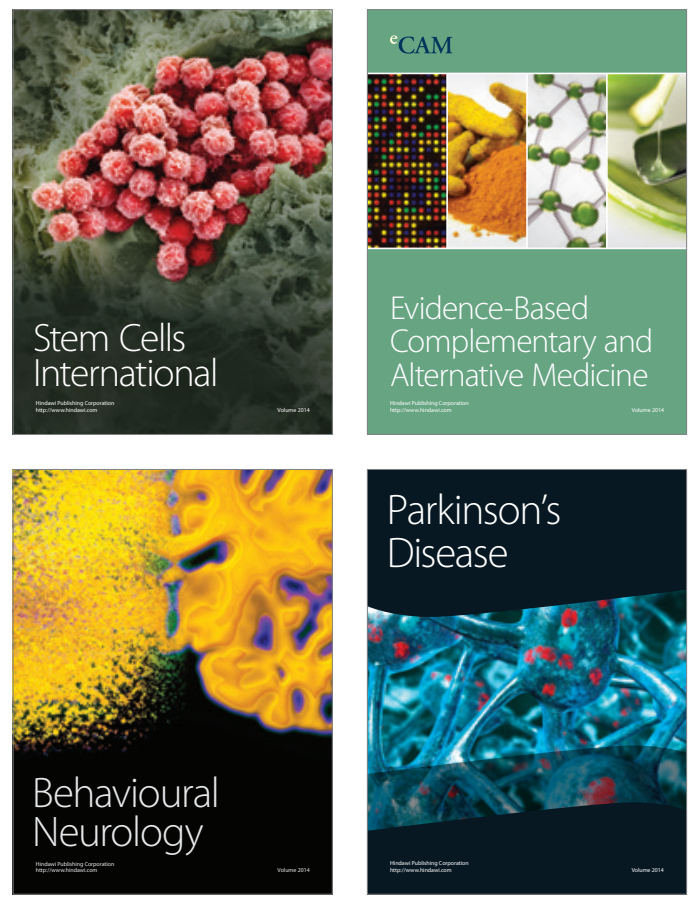
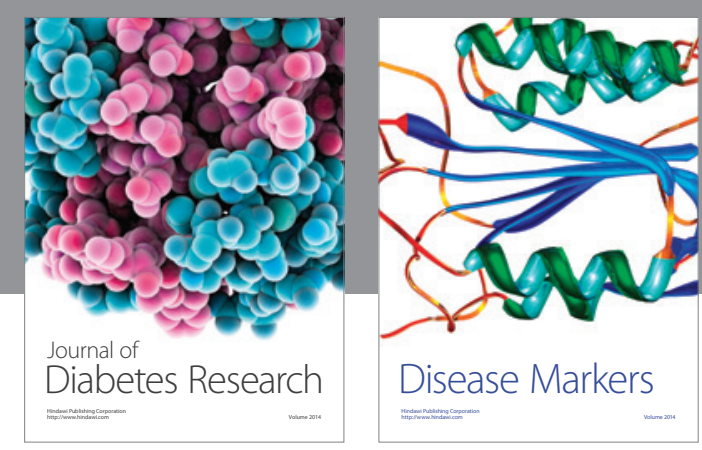

Disease Markers
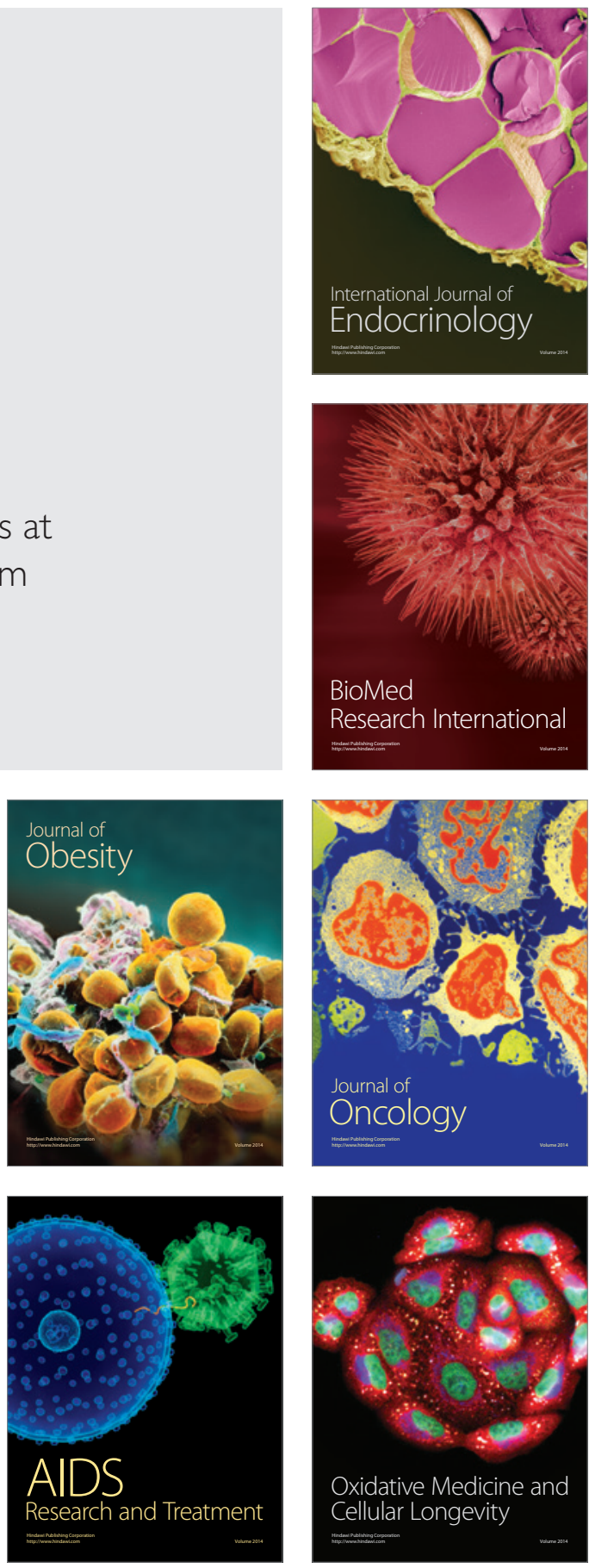